\title{
Development of Zirconium Thin Films by Pulsed Direct Current Magnetron Sputtering: Effect of Pulsed Parameters
}

\author{
Akash Singh", P. Kuppusami", R. Thirumurugesan, V. Ganesan² and E. Mohandas \\ *Physical Metallurgy Group, Indira Gandhi Centre for Atomic Research, Kalpakkam-603 102. \\ ${ }^{1}$ Centre for Nanoscience and Nanotechnology, Sathyabama Universiy, Chennai-600 119 \\ 2UGC-DAE Consortium for Scientific Research, University Campus, Khandwa Road, Indore.
}

\begin{abstract}
This paper characterizes phases present in thin $\mathrm{Zr}$ films at $773 \mathrm{~K}$ of substrate temperature. The effect of pulsed parameters such as pulse frequency, duty cycle and pulse power during the deposition of $\mathrm{Zr}$ film on $\mathrm{Si}(100)$ at the substrate temperature of $773 \mathrm{~K}$ has been studied. Formation of a-phase of zirconium was noticed with (001) preferred orientation at $773 \mathrm{~K}$. Preferred orientation was found to be influenced by the pulse parameters. It is noticed that crystallite size decreased with increasing frequency and duty cycle, whereas it increased with increasing pulse power. Nanoindentation measurements indicted that the hardness of the films was in the range 4-8 GPa as a function of pulsed parameters.
\end{abstract}

Keywords: Magnetron sputtering, Zirconium, Microstructure, Texture, Hardness

\section{INTRODUCTION}

Zirconium and its alloys in bulk and thin film forms are widely used in nuclear industry and in reprocessing plants owing to their exceptional resistance to corrosion [1]. Zirconium is a IV-group transition element and has superior corrosion resistance against concentrated nitric acid at elevated temperature. It is used as a material for chemical plants to produce nitric acid or spent nuclear fuel reprocessing plants. Good refractory properties of zirconium oxides and high hardness, electrical conductivity of zirconium nitrides provide wide scope for these materials for industrial applications [2-7].

Zirconium oxides and nitrides are also widely employed in industry because of their interesting properties: good refractory properties for oxides and high hardness and electrical conductivity for nitrides [8]. In that case, knowledge of the initial $\mathrm{Zr}$ film microstructure is of prime importance as it can influence on the reaction and the final product. The initial structure may be strongly dependent on the conditions used for the deposition process especially when using non- equilibrium growth mechanisms occurring with highly energetic ion bombardment. Thin films of zirconium oxides and nitrides can be prepared by the treatment of $Z r$ thin films under oxidizing or nitriding atmospheres [9]. $\mathrm{Zr}$ based hard coatings are of great interest in a number of technological and medical implant [10] applications due to their improved tribological, corrosion, mechanical and physical properties. Also, polycrystalline zirconium films are used in thin multilayer for various applications such as metallic super lattice formation [11-13]. Zirconium thin films have been suggested as a diffusion barrier between U-Mo fuel and aluminum cladding in order to maintain the integrity of the fuel plates and to prevent fuel plate swelling and possible rupture during reactor operation [14]. Zirconium and titanium films have been also deposited on copper substrate to produce neutrons through deuteriumdeuterium (D-D) and deuterium-tritium (D-T) reactions for neutron generator applications [15-16].

Sputtering is the most popular metal thin film deposition process. There exist commercially available codes [17-18] enabling the user to calculate the distribution of sputtered material at the substrate surface. Performing DC magnetron sputtering from a pure metal target in an ambient of Ar, the presence of oxygen in the 
processing chamber may result in some oxidation of the metal target surface. The thin oxide coating at the target may be charged by the bombarding ions. This will result in micro arcing at this surface. During such arcing micro particles may be formed resulting in a coating with undesirable inclusions of micro particles. To overcome this problem it has become quite popular to use a pulsed direct current (DC) power in the form of high negative pulses interrupted by small positive pulses (arc suppression) [19-20]. In this way the charge at the oxide surface on the target may be neutralized by attracting electrons during the positive part of the duty cycle. It has been shown that properly matched positive and negative pulses may allow for arc free reactive sputter deposition of insulating materials from pure metal targets. Therefore, it is necessary to select the right power source parameters during the synthesis of these films.

The effect of substrate temperature on the microstructure of Zr films at constant pulsed parameters has been reported and well grown hexagon shaped crystallites have been noticed at the substrate temperature of $773 \mathrm{~K}$ [21]. These films were deposited at $100 \mathrm{kHz}$ of pulse frequency, $20 \%$ of duty cycle and 100 $\mathrm{W}$ of pulse power. However the effect of pulsed parameters was not fully understood. In this work, the effect of pulse frequency, duty cycle and pulse power on the microstructure of $\mathrm{Zr}$ films deposited at $773 \mathrm{~K}$ is investigated. In the present study, a systematic investigation on the effect of pulsed parameters to achieve good quality films of $\mathrm{Zr}$ on titanium modified austenitic stainless steel ( D-9 alloy) substrates is reported.

\section{MATERIAL AND METHODS}

Zirconium target of $99.9 \%$ purity was used to deposit zirconium films of thickness in the range $1.2-1.5 \mu \mathrm{m}$ on to D-9 alloy substrates at $773 \mathrm{~K}$. D-9 alloy (whose composition is given in Table 1) is used as a clad material in breeder reactors. A zirconium target ( purity better than $99.9 \%$ ) of $76 \mathrm{~mm}$ diameter and $2 \mathrm{~mm}$ thickness was used to deposit zirconium films of thickness of $\sim 1.5 \mu \mathrm{m}$ on to titanium modified austenitic stainless steel (D-9 alloy)

D-9 alloy (whose composition is given in Table 1) is used as a clad material in breeder reactors. The sputtering was carried out using a Mighty Mak US sputtering gun of 3 inch diameter in a custom built magnetron sputtering system A RPG-50 asymmetric bipolar pulsed DC power supply (MKS instruments, USA) was used as the electrical power source for the sputter deposition. The substrate temperature was kept constant at $773 \mathrm{~K}$ using a halogen lamp $(800 \mathrm{~W}, 6.3 \mathrm{~A})$ heater with a digital programmable temperature controller. The sputtering method has been reported earlier [21]. The deposition conditions and pulsed parameters used in the present investigations are given in Table 2. During the sputtering, negative pulses were applied to the target, and the duration of pulses can be adjusted by varying the duty cycle of the pulse. Duty cycle can be defined as the ratio of on time and total time of the pulse. Duty cycle in the range $10-40 \%$, pulse frequency in the range $50-200$ $\mathrm{kHz}$ and pulse power in the range 50-125 W were applied to study the effect of these parameters on the microstructure of Zr films.

Table 1. Chemical composition (wt.\%) of titanium modified stainless steel (alloy D-9).

\begin{tabular}{|l|l|l|l|l|l|l|l|l|l|l|l|l|l|l|}
\hline Elem. & $\mathbf{C}$ & $\mathbf{N i}$ & $\mathbf{C r}$ & $\mathbf{M o}$ & $\mathbf{T i}$ & $\mathbf{S i}$ & $\mathbf{M n}$ & $\mathbf{S}$ & $\mathbf{P}$ & Al & $\mathbf{B}$ & $\mathbf{N}$ & $\mathbf{F e}$ \\
\hline Wt.\% & 0.05 & 14.9 & 14.7 & 2.2 & 0.18 & $\begin{array}{l}0.6 \\
5\end{array}$ & 1.3 & $<0.005$ & 0.008 & $<0.0034$ & 0.0015 & $<0.04$ & Bal \\
\hline
\end{tabular}


Table 2.Experimental parameters for deposition of $\mathrm{Zr}$ thin films

\begin{tabular}{|c|c|}
\hline Base pressure & $8 \times 10^{-4} \mathrm{~Pa}$ \\
\hline Operating pressure & $7.5 \times 10^{-1} \mathrm{~Pa}$ \\
\hline Target voltage & $205-230 \mathrm{~V}$ \\
\hline Substrate temperature & $773 \mathrm{~K}$ \\
\hline Pulse power & $50-125 \mathrm{~W}$ \\
\hline Duty cycle & $10-40 \%$ \\
\hline Pulse frequency & $50-200 \mathrm{kHz}$ \\
\hline Argon flow rate & $50 \mathrm{sccm}$ \\
\hline Substrate to target distance & $60 \mathrm{~mm}$ \\
\hline
\end{tabular}

The thickness of the films was measured using DEKTAK 6M-stylus profiler (Veeco, USA). Structural properties of the as deposited Zr films were characterized by $X$-ray diffraction (XRD). The XRD patterns were recorded in an INEL XRG - 3000 diffractometer with a glancing angle incidence $(\omega)$ of $5^{\circ}$ using $\mathrm{Cu}$ Ka radiation. The crystallite size was determined using the Scherrer formula. Texture coefficients (TC) of $\left(\begin{array}{lll}0 & 0 & 2\end{array}\right)$ and $\left(\begin{array}{lll}1 & 0 & 1\end{array}\right)$ reflections were determined from the intensities of $\mathrm{Zr}$ peaks. In general, the TC (Texture Coefficient) for any reflection can be determined using the following relation.
Texture Coefficient

$$
\text { (TC): } \frac{\frac{I_{m}(h k l)}{I_{0}(h k l)}}{\frac{1}{n} \sum \frac{I_{m}(h k l)}{I_{0}(h k l)}}
$$

where $n$, the number of peaks; Im, the measured peak intensities of reflections of Zr films; and 10, the respective peak intensities corresponding to the bulk $\mathrm{Zr}$ data from JCPDS File No. 05-0665. XL30 ESEM Philips scanning electron microscope (SEM) was used to analyze the surface morphology and composition of the films. Surface morphology of the films was also examined in an atomic force microscope(AFM) using Digital Instruments Inc., Nanoscope E, US in contact mode. The nanohardness measurements were carried out by means of a nanoindenter (CSM, Switzerland).

\section{RESULTS}

\section{A. The role of pulse frequency}

Fig.1 (a) shows XRD patterns of Zr films deposited on D-9 alloy substrate at $773 \mathrm{~K}$ and at various pulse frequencies $(50,100,150,200 \mathrm{kHz})$ and at constant pulse power and duty cycle of $100 \mathrm{~W}$ and $20 \%$, respectively. The Fig. 1 shows that films are polycrystalline in nature and all the reflections are from aZr. For the calculation of crystallite size, (002) and (101) reflections have been considered at different pulse frequencies and it is found that, the crystallite size decreases more rapidly above $100 \mathrm{kHz}$ of pulse frequency (Fig.1(c)). The deposition rate also decreases as pulse frequency increases (Fig. 1 (b)). It is observed that initially the $\mathrm{Zr}$ film exhibit (002) preferred orientation (Fig. 2) but with increasing pulse frequency (101) becomes the preferred orientation. 

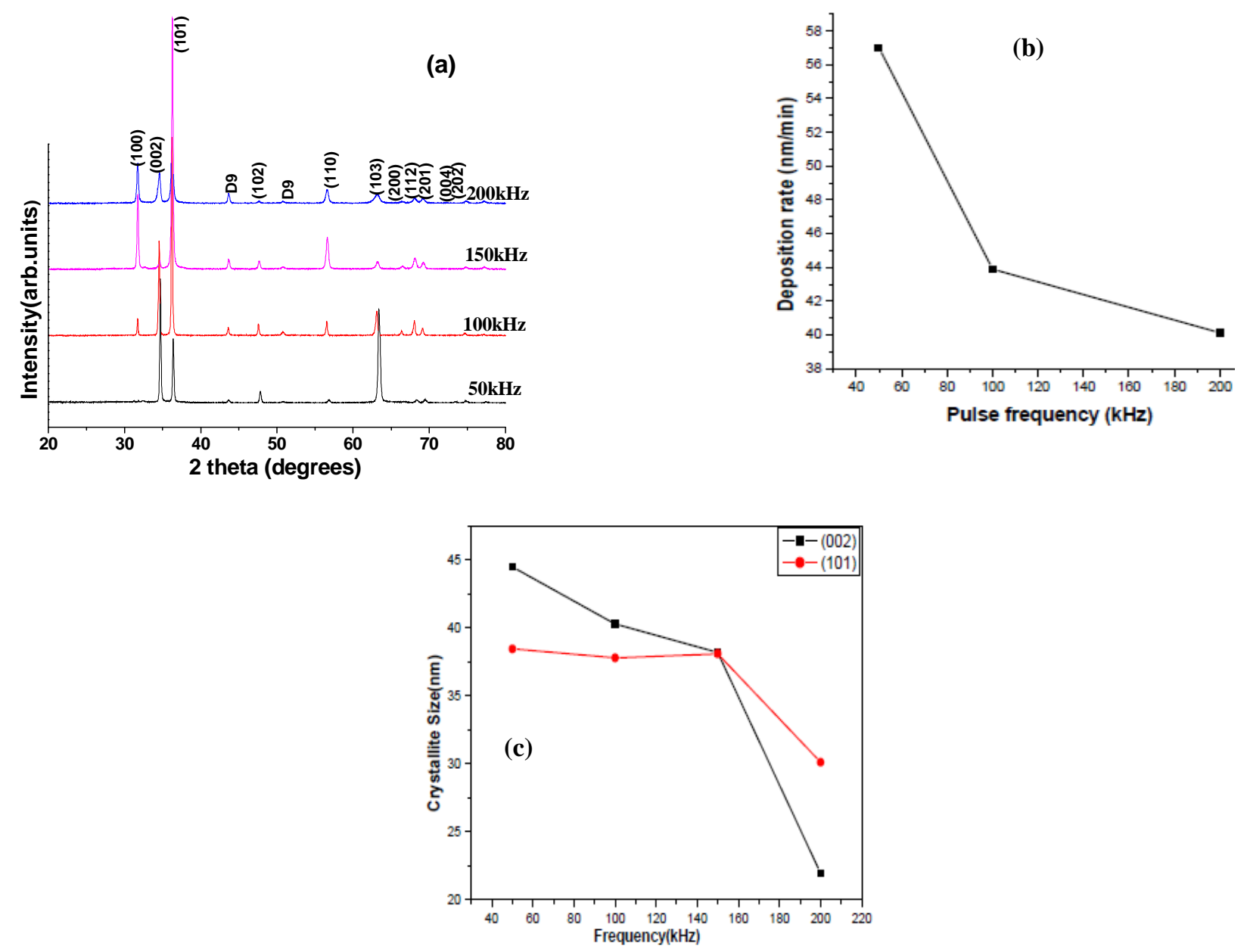

Fig. 1 (a) XRD pattern of Zr thin films as a function of pulse frequency, (b) Deposition rate and (c) Crystallite size versus pulse frequency.

Strain free lattice parameters ratios $\mathrm{c} / \mathrm{a}$ for all $\mathrm{Zr}$ films deposited at different pulse frequency is found to be higher than the reported value of c/a in bulk. SEM (Fig. 3) and AFM (Fig. 4) images clearly show the similar variation of crystallite size with increasing pulse frequency.

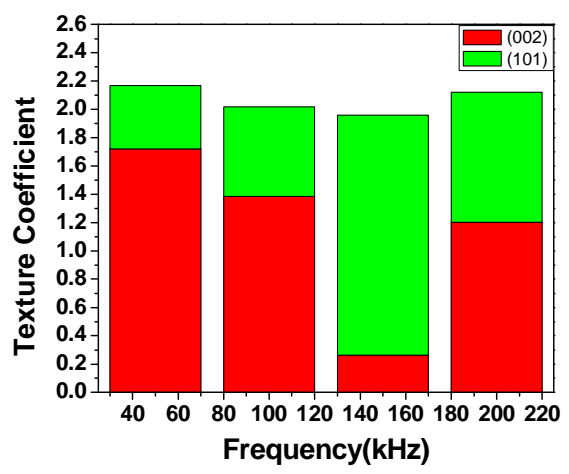

Fig.2 Texture coefficient versus pulse frequency 

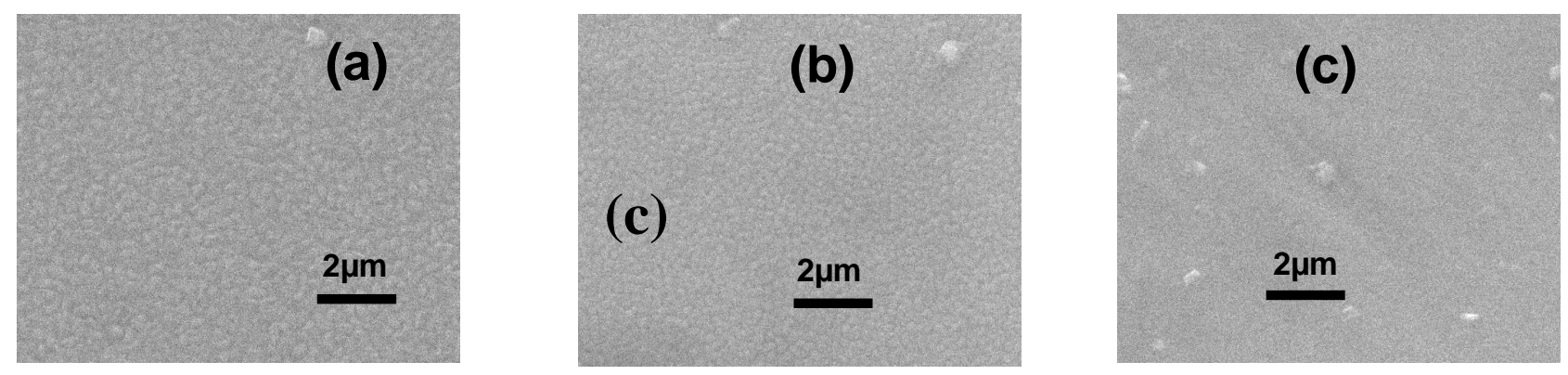

Fig. 3 SEM imageof Zr films deposited $773 \mathrm{~K}$ at pulse frequency of (a) 50, (b) 100 and (c) $200 \mathrm{kHz}$.
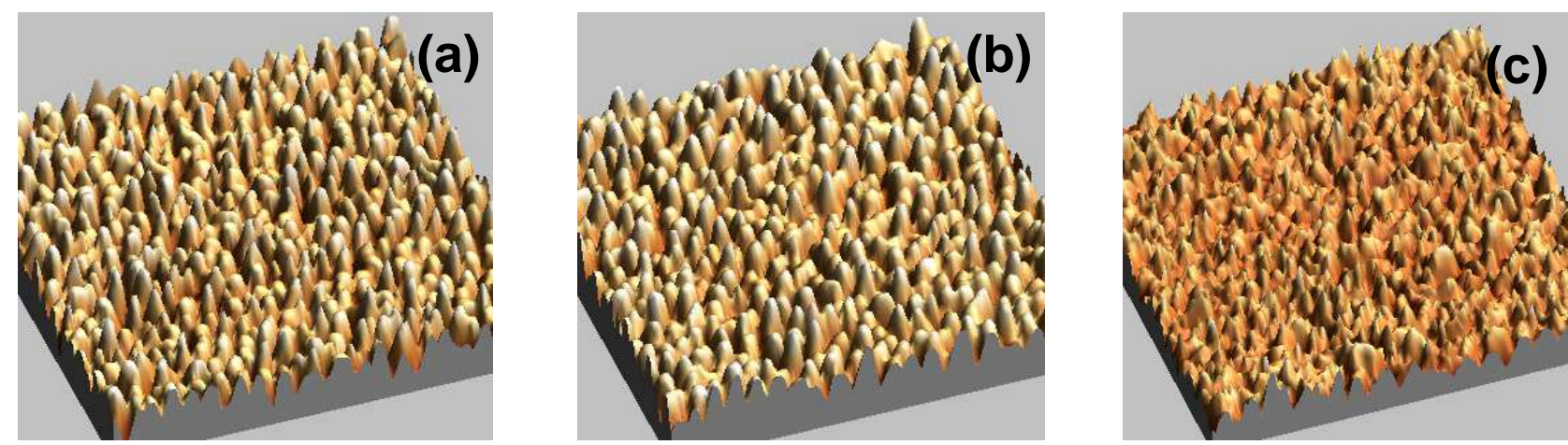

Fig. 4 AFM image ( $5 \mu \mathrm{m} \times 5 \mu \mathrm{m}$ ) of Zr films deposited at $773 \mathrm{~K}$ and at pulse frequency of (a) 50, (b) 100 and (c) $200 \mathrm{kHz}$

\section{B. The role of duty cycle}

Fig. 5 (a) shows XRD patterns of $a-Z r$ films deposited on D-9 alloy substrate at $773 \mathrm{~K}$ and various duty cycles (10\%, $20 \%, 30 \%$ and $40 \%)$ at constant pulse power of $100 \mathrm{~W}$ and constant pulse frequency of 100 $\mathrm{kHz}$. It is noticed that all the reflections present in the XRD pattern belongs to a-hcp phase of $\mathrm{Zr}$. The crystallite size was calculated using (002) reflection and is found to be decreasing with increasing pulse width. The XRD results also indicate that crystallinity decreases with the increase in the duty cycle (Fig. 5(c)). It is also noticed that the deposition rate increases with increase in duty cycle (Fig.5 (b)). Crystallite size decreases from $\sim 43 \mathrm{~nm}$ to 30 $\mathrm{nm}$ with increasing duty cycle from 10 to $40 \%$. It is observed that initially the Zr film exhibit (002) preferred orientation (Fig. 6) but with increasing duty cycle (101) becomes the preferred orientation. The anisotropic grain growth, thermal stress and texture of the grains are responsible for evolution of three-dimensional hexagonal structures at higher duty cycle. The anisotropic grain growth may occur in $\mathrm{Zr}$ thin films due to the factors such as preferred orientation of the grains, orientationdependent grain boundary mobility and grain boundary free energy. AFM (Fig. 7) images clearly show the variation of crystallite size with increasing duty cycle. Surface roughness was also calculated and is found to be decreasing from 10 to $7 \mathrm{~nm}$ as a function of duty cycle 

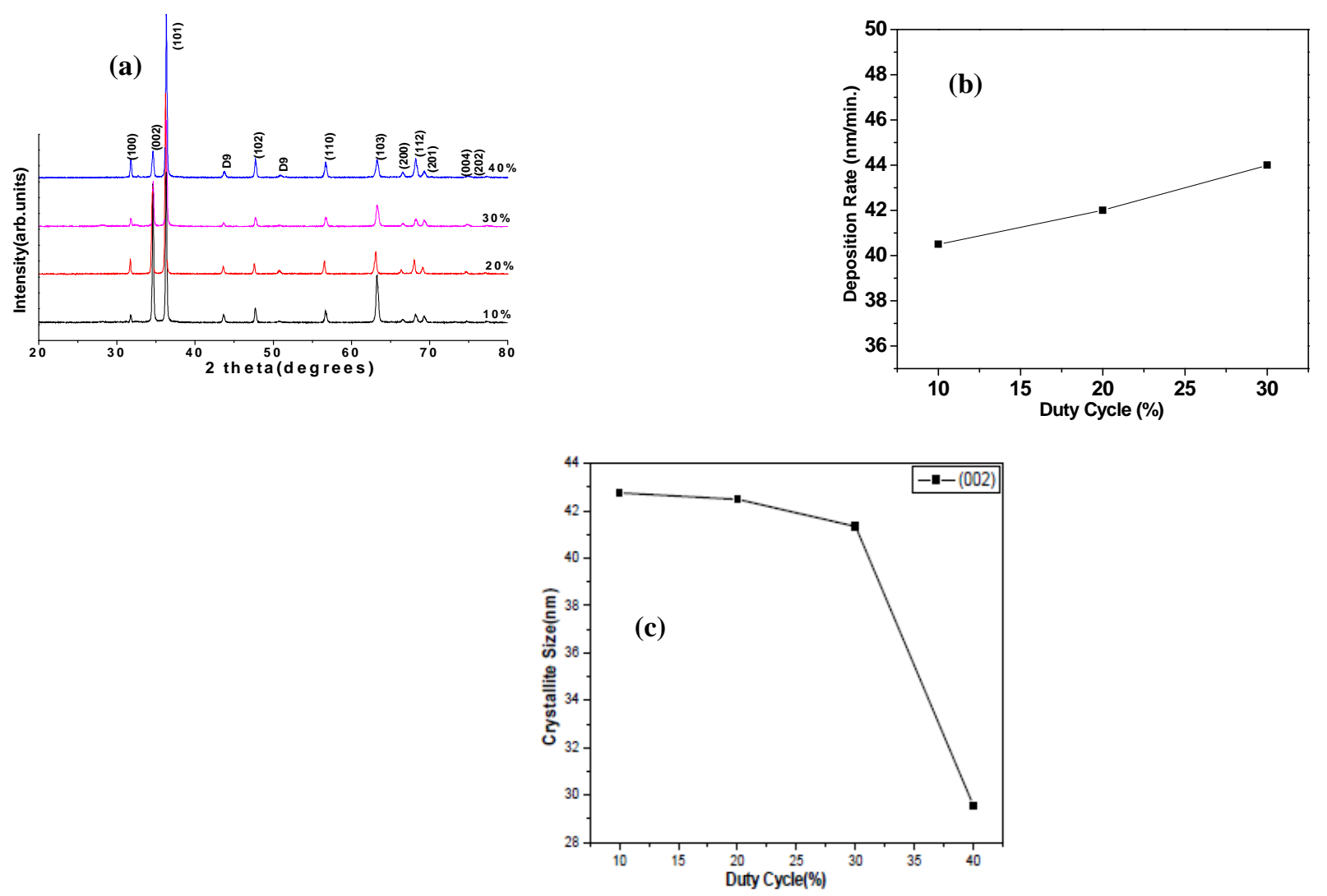

Fig. 5 (a) XRD pattern of Zr thin films as a function of pulse width, (b) Deposition rate and (c) Crystallite size versus duty cycle.

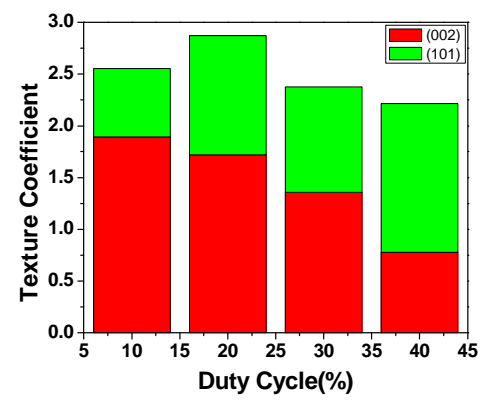

Fig 6 Variation of texture coefficientin Zr film deposited on D-9 alloy as a function of duty cycle

\section{C.The role of pulse power}

Fig. 8 (a) shows the XRD pattern of Zr thin films deposited on D-9 alloy substrate at $773 \mathrm{~K}$, pulse power of $50,75,100$ and $125 \mathrm{~W}$ constant frequency of $100 \mathrm{kHz}$ and constant duty cycle of $20 \%$. Fig. 8 (c) demonstrates the qualitative dependence of the crystallite size on the pulsed DC power. It is also noticed that the crystallite size and deposition rate (Fig.8 (b) \& (c)) increases with increasing power. Crystallite size was calculated using Scherrer's formula for the (002) and (101) reflections of the $\mathrm{Zr}$ pattern obtained as a function of different pulse power. For the Zr films deposited at 50, 75, 100 and 125 $W$, the corresponding crystallite size is $\sim 30,35,47$ and $62 \mathrm{~nm}$ respectively. It is observed that the $Z \mathrm{r}$ film exhibits $\left(\begin{array}{lll}0 & 0 & 2\end{array}\right)$ and (101) preferred orientation with increasing power (Fig. 9). AFM (Fig.10) images clearly show well grown crystallites at higher pulse power. 

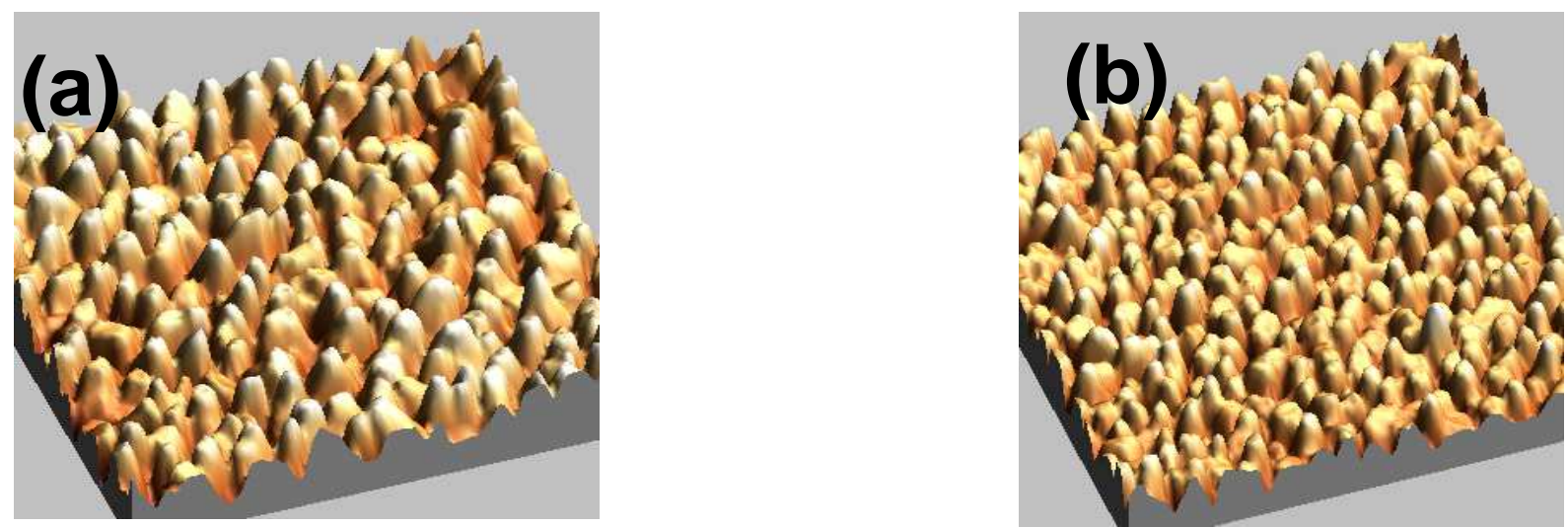

Fig. 7 AFM image ( $2 \mu \mathrm{m} \times 2 \mu \mathrm{m}$ ) of Zr films deposited at $773 \mathrm{~K}$ and at (a) $10 \%$ and (b) $30 \%$ of duty cycle
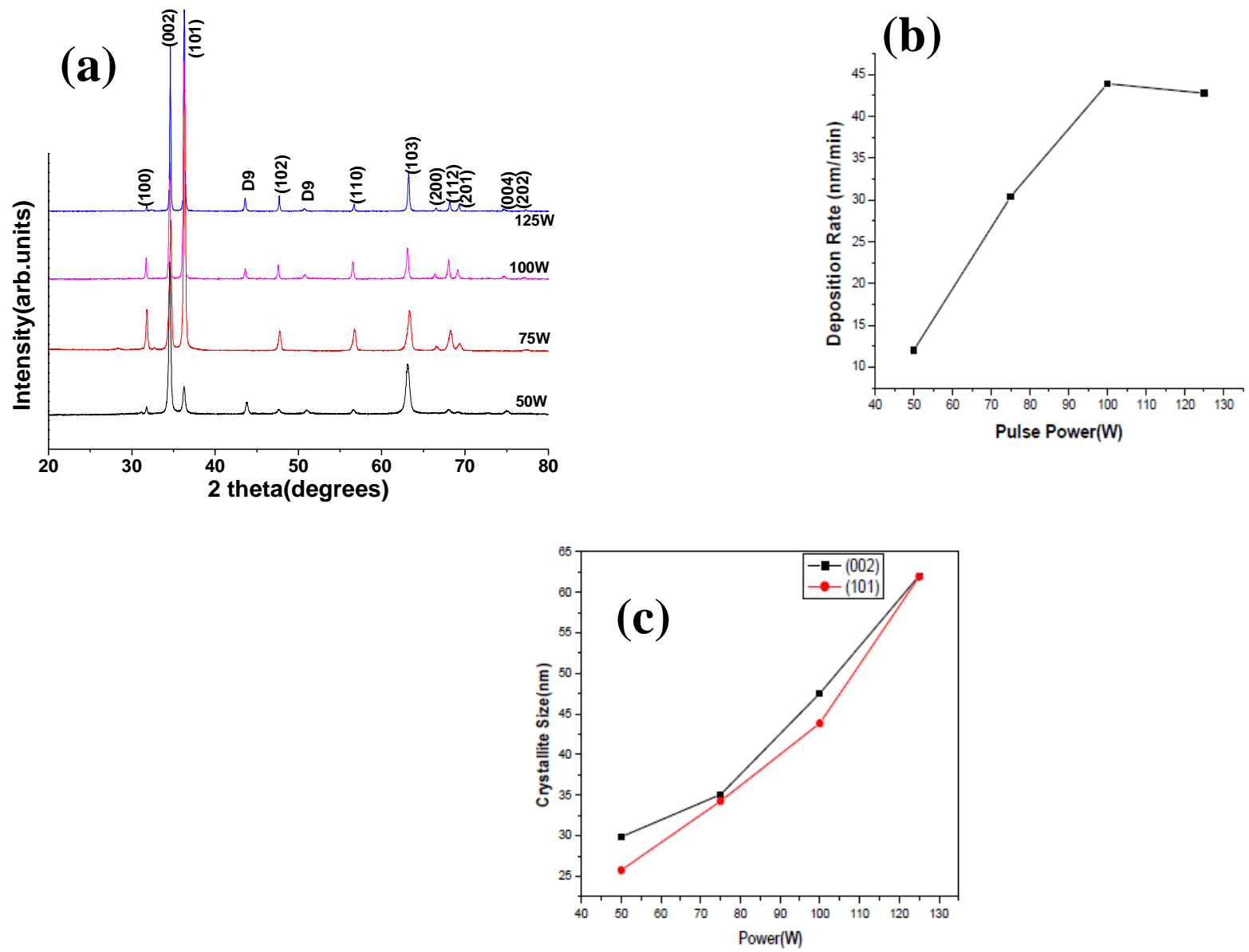

Fig. 8 (a) XRD pattern of Zr thin films as a function of pulse power, (b) Deposition rate and (c) Crystallite size versus pulse power. 


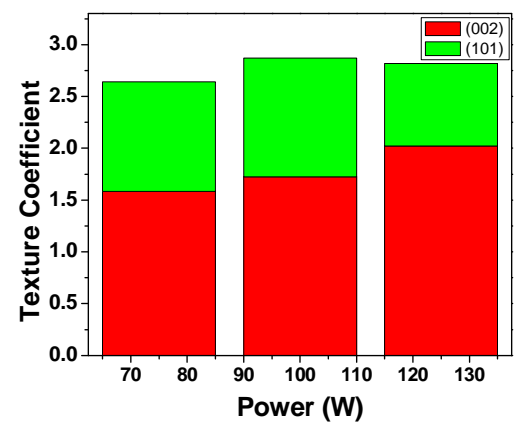

Fig. 9 Texture coefficients as a function of duty cycle
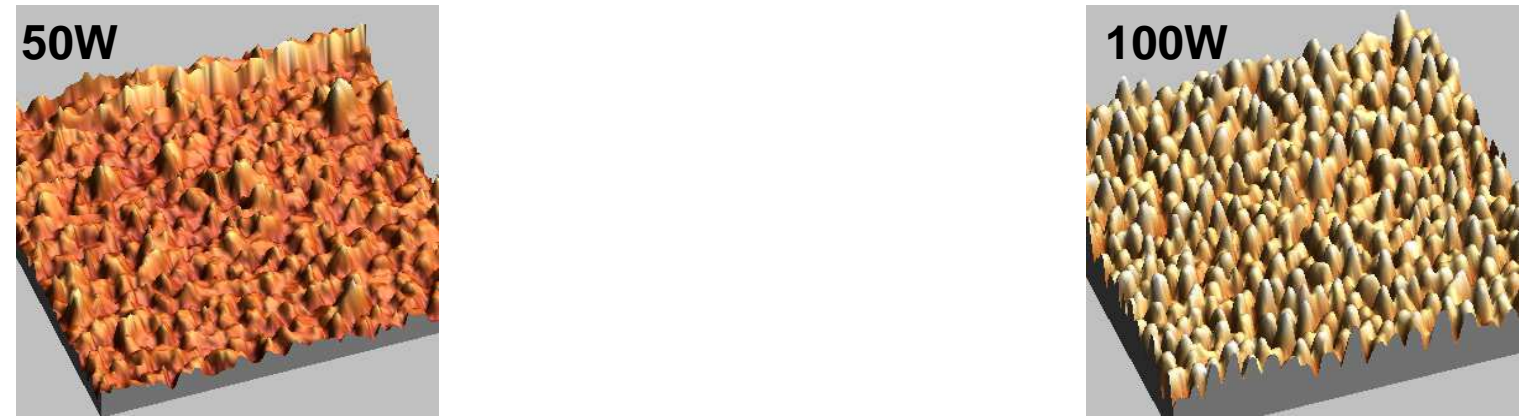

Fig. 10 AFM image ( $5 \mu \mathrm{m} \times 5 \mu \mathrm{m}$ ) of Zr films deposited at (a) $50 \mathrm{~W}$, (b) $75 \mathrm{~W}$ and (c) $100 \mathrm{~W}$ of pulse power

\section{D.Nanohardness of Zr thin films}

In the present study film thickness was about 1.5 micrometer. Hardness was determined by nanoindentation and to avoid the contributions from the substrate the indentation depth performed ranged from 100 to $150 \mathrm{~nm}$ to ensure the correctness of this method for measuring mechanical properties of the thin films. For measuring hardness and modulus using the nanoindentation method with a Berkovich indenter, indentation load, $\mathrm{P}$, with displacement, $\mathrm{h}$, is continuously recorded during one complete cycle of loading and unloading [22]. Hardness represents a complex combination of the deformation characteristics of thin films. Table 3 shows the variations of hardness and elastic modulus as a function of pulsed parameter for the $\mathrm{Zr}$ films. The hardness values of the $\mathrm{Zr}$ films range from 4-8 GPa. Nanoindentation measurement indicate that the hardness of the film was about 6-8 GPa as a function of pulse frequency and duty cycle variation.
Table 3 Hardness and Elastic Modulus variation as a function of pulse parameters

\begin{tabular}{|c|c|c|c|}
\hline \multicolumn{2}{|c|}{ Parameters } & $\begin{array}{c}\text { Hardness } \\
\mathbf{\pm 1}(\mathrm{GPa})\end{array}$ & $\begin{array}{c}\text { Elastic } \\
\text { Modulus } \\
\pm 20(\text { GPa })\end{array}$ \\
\hline Freq. $(\mathrm{kHz})$ & 50 & 4.87 & 155.17 \\
\hline & 100 & 6.40 & 198.67 \\
\hline & 200 & 6.57 & 153.45 \\
\hline Duty Cycle \% & 10 & 6.15 & 162.39 \\
\hline & 20 & 6.40 & 198.67 \\
\hline & 30 & 6.42 & 170.81 \\
\hline Power (W) & 50 & 7.8 & 205.6 \\
\hline & 100 & 6.40 & 198.67 \\
\hline
\end{tabular}




\section{DISCUSSIONS}

\section{A.Effect of Pulse Power Supply Parameters on the Growth Characteristics}

The crystallite size and deposition rates of Zr films are significantly influenced by some of the pulse parameters reported in the present work.

The deposition process is usually carried out with pulse frequencies (fP) in the range $50-250 \mathrm{kHz}$. Increasing the pulse frequency increases the bombardment of target by high energy Ar atoms [23], leading to increased flux of sputtered atoms [24], which results in the decrease in the surface mobility of these species. As a consequence there is a reduction in the crystallite size. The growing film is bombarded by ions of appropriate energy to cause modification of its structure and properties, and the rate of arrival of the ions, and hence the degree of structural modification can be controlled by varying the pulse frequency. Also, the average power dissipated at the target decreases with increasing pulse frequency and at the start of each pulse there is a dead time during which negligible sputtering occurs and the proportion of this dead time increases with increasing pulse frequency and so the deposition rate is lower at a higher frequency $[23,25]$. The rate of voltage change at the target during the initial stages of the pulseon period and the maximum negative voltage attained during the pulse-on period is significantly lower at higher frequencies [25]. Since sputtering rate is proportional to power and sputtering yield is proportional to target voltage, both these factors tend to lower the deposition rate at a higher frequency (Fig. 1(b)).

Pulse width is related to the duty cycle of the pulse and it is indirectly related to pulse frequency also. Duty cycle of any pulse can be defined as the ratio of on time of the pulse (pulse width) to the total time (on and off time) of the pulse. Duty cycle is the proportion of time during which electrical power source is operated. It controls the discharge duration of a single pulse and increasing the duty cycle at constant power increases the deposition rate (Fig. 5(b)). Duty cycle may provide a useful means for controlling film compositions. This is due to the fact that the duty cycle determines the sputtering duration on each target and the amount of sputtered species. At higher duty cycle, the time for sputtering increases, which reduces the time for discharge for the accumulated species on the target and as a consequence the mobility of the accumulated species in the substrate decreases which leads to a decrease in the crystallite size as seen in the Fig. 5(c).

High pulse power in the magnetron sputtering process creates highly energized Ar ions which imparts kinetic energy to the sputtered atoms. Therefore the surface diffusion of these species is then enhanced on the growing surface, which leads to increased crystalline size. Also, the average power dissipated at the target increases with increasing pulse power which increases the deposition rate of the film as seen in Fig. 8(b). The $\mathrm{XRD}$ analysis of the $\mathrm{Zr}$ films with varying sputtering power indicated mixed orientation. It may be interpreted on the basis of stress present the film with increasing film thickness. The compressive stress induced in the films contributes to the development of $\left(\begin{array}{lll}1 & 0 & 1\end{array}\right)$ orientation and it may have relaxed to tensile mode at higher thickness (obtained with higher power ) favoring the $\left(\begin{array}{lll}0 & 0 & 2\end{array}\right)$ preferred orientation.

\section{B.Nanohardness of Zr thin films}

Possible explanations for the larger hardness in the $\mathrm{Zr}$ films at $\mathrm{Ts}=773 \mathrm{~K}$ are a combination of smaller grain size, texture strengthening [26] and a nano-size effect, which is discussed in the following. The dependence of hardness on grain size agrees well with the well-known Hall-Petch [27-28] relation as

$$
\mathrm{H}=\mathrm{H} 0+\mathrm{KHd}-1 / 2
$$

where $\mathrm{H}$ is the hardness, $\mathrm{d}$ being the average grain diameter, $\mathrm{KH}$ being the slope of the straight line drawn through the data, and $\mathrm{HO}$ is the intercept of the line with the coordinate axis. However no change in hardness value was observed with respect to pulsed parameters such as pulse frequency and duty cycle due to small variation in the crystallite size within the range of investigation. A slight increase in the hardness value as 
a function of pulse power may be related with lower crystallites at low pulse power.

\section{CONCLUSION}

Formation of a-phase of zirconium with (002) preferred orientation was noticed at $773 \mathrm{~K}$ as a function of pulse parameter. It was found that crystallite size decreases with increasing frequency and duty cycle, whereas crystallite size increases with increasing pulse power. Nanoindentation measurements indicted that the hardness of the films is in the range 4-8 GPa. With proper pulse parameter selection It was noticed that well grown crystallites with a- hcp phase of zirconium at $773 \mathrm{~K}$ and $100 \mathrm{kHz}, 20 \%, 100 \mathrm{~W}$ of pulse frequency, duty cycle, pulse power respectively.

\section{ACKNOWLEDGEMENT}

The authors are thankful to Smt. M. Jyothi and Dr. Ramaseshan for their help in XRD and nanoindentation study. They are also grateful to Dr. M. Vijayalakshmi, AD, PMG, Dr. T. Jayakumar, Director, Metallurgy and Materials Group and Dr. Vasudev rao, Director, IGCAR for the support and encouragement.

\section{REFERENCES}

[1] H.O. Pierson, New Jersey, USA, 1996, 181.

[2] S. Ramanathan, C.M. Park, P.C. Mclntyre, J. Appl. Phys. 91 (2002) 4521.

[3] S. Niyomsoan, W. Grant, D.L. Olson, B. Mishra, Thin Solid Films 415 (2002) 187.

[4] S. Miyazaki, M. Narasaki, M. Ogasawara, M. Hirose, Solid State Electron. 46 (2002) 1679.

[5] N.L. Zhang, Z.T. Song, Q. Wan, Q.W. Shen, C.L. Lin, Appl. Surf. Sci. 202 (2002) 126.

[6] H.M. Benia, M. Guemmaz, G. Schmerber, A. Mosser, J.C. Parlebas, Appl. Surf. Sci. 200 (2002) 231.

[7] L.Q. Shi, G.Q. Yan, J.Y. Zhou, S.Z. Luo, S.M. Peng, W. Ding, X.G. Long, J. Vac. Sci.Technol. A 20 (2002) 1840.

[8] L.E.Toth, Transition Metal Carbides and Nitrides. Academic Press, New York, (1971).

[9] L. Pichon, T. Girardeau, F. Lignou, A. Straboni, Thin Solid Films 342 (1999) 93.
[10] M. Balaceanu , T. Petreus, V. Braic, C.N. Zoita , A. Vladescu, C.E. Cotrutz , M. Braic, Surf. Coat. Technol. 204 (2010) 2046.

[11] A. Baudry, P. Boyer, M. Brunel, J. Magn. Mater. 185 (1998) 309.

[12] D.J. Li, M.X. Wang, J.J. Zhang, Mater. Sci. Eng. A 423 (2006)116.

[13] L. Smardz, J. Alloys Compd. 395 (2005) 17.

[14] Kendall J. Hollis ,International Thermal Spray \& Surface Engineering, Editors, Robert Gansert, William Jarosinski, Nov. 2010, 5 (4).

[15] F.Abbasi, G.R.Etaati, H.Afarideh, R.Koohi-Fayegh, G.R.Aslani, Iranian J.Phys.Res. .3, No.2. (2002)101.

[16] F. Abbasi Davani, R. Koohi Fayegh, H. Afaride, G.R. Etaati, G.R. Aslani, Radiation Measurement 37 (2003) 237.

[17] J.P. Biersack, L.G. Haggmark, Nuclear Instrum. Methods Phys. Res.174 (1980) 257.

[18] SIMBAD - Thin Film Process Simulator.\#318,11315-87 Avenue, Edmonton, Alberta, Canada T6G 2T9: Alberta MicroelectronicCenter, 1997.

[19] S. Schiller, K. Goedicke, J. Reschke, V. Kirchhoff, S. Schneider, F.Milde, Surf. Coat. Technol. 61 (1993) 331.

[20] H. Ohsaki, Y. Tachibana, J. Shimizu, T. Oyama, Thin Solid Films281/282 (1996) 213.

[21] A. Singh, P. Kuppusami, R. Thirumurugesan, R. Ramaseshan, M. Kamruddin,S. Dash, V. Ganesan, E. Mohandas, Appl. Surf. Sci.257 (2011) 9909.

[22] J.L. Loubet, J.M. Georges, O. Marchesini, G. Meille, ASME J. Tribol.106 (1984) 43.

[23] Y.T. Pei, C.Q. Chen, K.P. Shaha, J.Th.M. De Hosson, J.W. Bradley, S.A. Voronin, M.Cada, Acta Mater. 56 (2008) 696.

[24] Y.T. Pei, K.P. Shaha, C.Q. Chen, R. van der Hulst, A.A. Turkin, D.I. Vainshtein, J.Th.M. De Hosson, Acta Mater. 57 (2009) 5156.

[25] P.J. Kelly, A.A. Onifade, Y. Zhou, G.C.B. Clarke, M. Audronis, J.W. Bradley, Plasma Processes Polym. 4 (2007) 246.

[26] S.E. Hsu, G.R. Edwards, J.C. Shyne, O.D. Sherby, J. Mater. Sci. 12(1977) 131

[27] E.O. Hall, Proc. Phys. Soc. Lond., B 64 (1951) 747.

[28] N.J. Petch, J. Iron Steel Inst. 174 (1953) 25. 